\title{
The Construction of Learning Oriented Enterprise Organization Based on Knowledge Management
}

\author{
Long Minghui \\ College of Management, Wuhan Donghu University, Wuhan, China
}

\section{Email address:}

615988649@QQ.COM

\section{To cite this article:}

Long Minghui. The Construction of Learning Oriented Enterprise Organization Based on Knowledge Management. International Journal of Elementary Education. Vol. 5, No. 4, 2016, pp. 40-46. doi: 10.11648/j.ijeedu.20160504.11

Received: August 1, 2016; Accepted: August 24, 2016; Published: August 25, 2016

\begin{abstract}
Knowledge management is a new management mode to meet the requirements of knowledge economy era. Knowledge has become the primary resource of enterprise organizational development, and it is the key to the enterprise competition and economic development. Learning organization theory is a new organization theory developed by the end of last century. In the process of practice, the theory of learning organization and knowledge management are closely related. Learning organization is one of the carriers of knowledge management, and knowledge management is the core and essence of the learning organization. They promote each other, meanwhile, they provide a strong impetus for the strengthening of the key competitiveness and the sustainable development of the organization. On the basis of summarizing the results of knowledge management and learning organization theory, the way and method of the combination of knowledge management and learning organization will be discussed in this paper. The aim is to provide reasonable strategic measures for modern enterprises to improve the management level of enterprises and foster the core competitiveness of enterprises.
\end{abstract}

Keywords: Knowledge Management, Learning-Type Organization, Excitation Mechanism

\section{Introduction}

The theory of learning organization is one of the two top management theories, which originated from the study of organizational learning. Early research was mainly focused on the individual learning in the organization, the representative figures are Chandler, Schon, March, Cyert. By the end of 80s, the focus shifted to the connection between individual learning and organizational learning. By 90s, Peter M. Senge, a professor at the Massachusetts Institute of technology in the United States, published a book The Fifth Discipline- the art and practice of learning organization. This book has aroused great repercussions in the academic and business circles, and since then, the research and practice of learning organization has flourished, becoming one of the most popular research fields.

Knowledge economy is sweeping the world, and it brings a profound impact to the world economic development. With the rapid progress of technology and the increasing uncertainty of the external environment, more and more enterprises directly feel the pressure from the outside world. The traditional production factors and management methods clearly can not meet the requirements of the outside world. In this case, the knowledge management arises at the historic moment, and is being developed at a rapid pace. In order to adapt to the outside world, the enterprise organization must first be a learning organization. It takes the organization as the main body of the study, can make the enterprise staff become the learner, and let the staff continue to study. However, in practice, the enterprise organization can not effectively integrate enterprise resources, knowledge management system and learning organization are not organically combined.

In the context of increasingly complex environment, building a learning organization around the problem of Chinese enterprises, has important theoretical and practical significance. The basis of knowledge management and learning organization theory is the western private enterprise, however, some differences in the management system, organizational form, and the cultural environment between western and Chinese enterprises exist. Therefore, the research based on the experience and theoretical study of the 
construction of learning organization in the western enterprise organization, combining with the actual situation of China's enterprise organization has more practical significance. On the basis of absorbing and learning from previous studies, the research object of enterprise is placed in the environment of the system in this paper, which makes full use of learning organization management theory and knowledge management theory to enhance the core competitiveness of enterprises. It has revealed that the core competence lies in the accumulation of knowledge capital, operation and integration, Enterprises should take the building of learning organization as a systematic project, focus on promoting organizational learning, management innovation, organizational change, technology development and other systems, which provides a new idea and method for the organization reform and management innovation of Chinese enterprises.

\section{The Concept of Knowledge Management}

The concept of knowledge management began in 1980s; it is a new theory that emerged with the development of knowledge economy. The content of knowledge management is very rich. Up to now, the academic community has not yet formed a consensus definition. Different scholars and organizations have different understand of knowledge management. Representative views are as follows: Horton, puts forward the concept of knowledge management from resource evolution view. Skyrme stressed the importance of knowledge to increase the value of the business. He also proposed to attach importance to the network knowledge sharing between groups and organizations within the network knowledge economy. K. Wiig put forward that the knowledge management organization is a system, and the knowledge assets should be fully explored and used. Karl Erick Sveiby thinks that knowledge management is the art of creating value by using the intangible assets of knowledge. Marianne Broadbent believes that knowledge management is a kind of objective management process to excavate and organize the personal and related knowledge to improve the overall efficiency. $\mathrm{Wu}$ Jiapei a domestic scholar, believes that knowledge management is the extension and development of information management, and information management is the basis of knowledge management. This definition emphasizes the origin of knowledge management and the relationship between knowledge management and information management. Ding Wei believes that knowledge management is the management of information, the deepening and development of information management on the one hand, it is the management of people, mining the hidden knowledge in the human brain to be fully shared, so as to improve the organization's competitiveness on the other hand. Based on the above definition, we can conclude that knowledge management is more inclined to be knowledge sharing, information system, organizational learning, intellectual capital management, performance management and strengthening.

\section{The Combination Mechanism of Knowledge Management and Learning Organization}

As a kind of theory, learning organization is not only a kind of management strategy, but also an organization formation. However, knowledge management is a kind of management method to construct ideal organization form. Learning organization and knowledge management can be regarded as the relationship between the target and the means, and can be seen as two parallel relationships. At present, there are five models in the international academic circles and the systematic learning organization model and so on. Peter M. Senge's five disciplines model is the most classical .His model proposes that self transcendence, improving mental models, shared vision, team learning and system are five bases to establish the practice thinking and build a learning organization from the system dynamics. In the domestic academic circles, Chen Guoquan process model of the learning organization construction $(6 \mathrm{p}-1 \mathrm{~b}$ model), and the model insist that organizational learning is consisted of discovery, invention, selection, implementation and promotion, feedback, knowledge base and knowledge management seven processes. Enterprises in the organization learning process should have the corresponding seven kinds of ability. The virtual team knowledge sharing model was established by Ye Wen and others who take the extended meta memory as the core.

\subsection{The Similarity of Knowledge Management and Learning Organization}

The position and function of knowledge in organization development should be paid more attention to. Knowledge management is through the transformation and innovation of knowledge to realize the appreciation. However, the learning organization emphasizes the importance of learning behavior to the organization.

Knowledge management and learning organization will share and make use of knowledge in an important position, which is intended to improve the level of knowledge use of the organization and the ability to solve problems. Knowledge management is an advanced technology and a certain platform to facilitate the sharing of knowledge, however, Learning organization promote the flow of knowledge within the organization which is through individual learning and organizational learning. In addition, Knowledge management reduces the distance of organization members to acquire knowledge through management mechanism. Learning organization is through the improvement of the structure to cultivate enterprise culture, to establish good communication channels and promote the knowledge sharing among the members. 


\subsection{The Difference Between Knowledge Management and Learning Organization}

Knowledge management emphasizes the sharing and innovation of knowledge, which is the starting point of knowledge management. However, learning organization emphasizes learning and good learning atmosphere, and its standpoint is to adapt to the change of environment by changing environment. In the management mode, the knowledge management emphasizes the difference among the members, which can bring the exchange of value. Learning organization emphasizes the tendency of understanding. So individual should take the initiative to adapt to the organization environment.

\section{An Analysis of the Factors Influencing the Knowledge Management Model of Learning Organization}

\subsection{External Environmental Factors Analysis}

External environment is an important condition for the survival and development of enterprises, which can provide resources and power for the sustainable development of enterprises. On the bases of the overall judgment and analysis of the external environment, the purpose is to achieve sustainable development through the construction of a knowledge-based enterprise whose learning organization can accurately grasp the opportunity and threat. External environment can be divided into general external environment and specific external environment. General external environment includes economy, politics, culture, technology, and legislation. Generally, when these factors change, the organization will also have some major changes. The specific external environment includes elements that have a direct impact on the development of the organization, such as service objects, managers, suppliers, etc.

\subsection{Internal Environmental Factors Analysis}

Internal environment includes enterprise's organization, management system, technical condition, human resource and so on. Compared with the external environment, the internal environment is relatively easy to control. Besides, internal environment will be more comprehensive and effective to establish the learning oriented organizational objectives. For example, the management system is mainly the combination of management mechanism and institutional norms, which is conducive to help learning organizations to achieve specific knowledge management activities.

\section{The Problems Existing in the Current Chinese Enterprises to Create Learning Organization}

\subsection{The Integration of Knowledge Management and Learning Organization Is Not Enough}

At present, the management ability and level of Chinese enterprises have been greatly improved, however, the overall situation is still not optimistic. In some state-owned enterprises, the centralized management mode is still implemented. Such a management system is not only increasing the risk of enterprise management, but also easily result the division of management. Lack of overall arrangement and management has greatly hindered the development of state-owned enterprises. Currently theoretical research on knowledge management and learning organization is constantly deepening, however in practice, knowledge management and activities of learning organization are still separation, which is not conducive to the effective integration of enterprise resources and sustainable development.

\subsection{Lack of the Support of Learning Oriented Enterprise Culture}

Learning enterprise culture is a kind of organizational culture in the process of the development of enterprise culture, which leads to the development of the enterprise as a kind of organizational culture. The culture of learning enterprise attaches great importance to the human factors, especially the overall quality of the people. Focusing on the coordinated development of enterprises and employees is the embodiment of the highest level of human management.

Learning oriented corporate culture is a kind of learning which encourages the members of enterprises to actively carry out individual and team learning. It improves the level of knowledge and professional skills of the organization by learning new knowledge and new achievements. Although the enterprise culture has been carried out for many years, but the concept of humanization and service has not really been deeply rooted in hearts of the people and the cultural quality of some leaders need to be improved. At present, most enterprises are still bound by a number of institutions, which is lack of common values and systems.

\subsection{Learning Effectiveness Is Not Strong}

First of all, the awareness of the staff is not sufficient; there is a deviation, lacking of initiative and consciousness. Secondly, team cooperation is weak and lack top-down source power. In the process of creating a learning organization, due to the limitation of their own professional ability, organization members are often only concerned about their own works, lacking of confidence and challenges to the new work, which will be difficult to strengthen the organization and cooperation and create a high level of cooperation team. Compared with the complex external environment, there are many problems 
in the management mode, risk awareness, financial management and so on. Management innovation is not only the behavior of managers, but also is a systematic and organized activity.

\section{The Countermeasures and Suggestions for Enterprises to Create Learning Organization Based on Knowledge Management}

\subsection{Setting Up the Value of Learning Organization}

The establishment of learning oriented organizational values can make all the members of the enterprise organization to form a continuous learning value. The famous management scholar Peter M. Senge made in "the fifth discipline" establishing learning organization that brings together the five disciplines or skills: first practice is to transcend; the second is improving mental models; the third is to establish a common desire; the four is learning group; the Fifth is systems thinking. The concept of learning organization should be specific to the specific production practice of the organization, including the development of strategic objectives and management practices. In addition, no matter organization or employee, should have a lifelong learning attitude. Only continuous learning will promote their own development and make greater contributions to the organization.

\subsection{Construction of Learning Organization Structure}

Learning organization should be a flat organizational structure, and enterprise members should be able to fully communicate about learning and knowledge. Due to the rigidity of the organizational structure of some enterprises, the establishment of learning organization has been restricted, which leads to the weak perception ability of the internal and external environment, delaying the development of the enterprise. When enterprises create learning organizations ,it should simplify the management level of a wide range of organizations, broaden the range of management, and reduce the loss of the information in the transmission process so as to improve the efficiency of information and knowledge transfer and strengthen the ability to quickly respond to changes in the external environment and decision-making in the organization.

Introducing organizational learning theory into the internal mechanism of management innovation is a learning reform of management innovation. The goal of enterprise organization reform is to establish a modern enterprise with advanced management level, and to realize the change of management mode. Among them, learning organization is an important way to solve the traditional management defects of enterprise organization. In the first place, learning organization can enhance the management ability and anti- risk capability. Learning organization will encourage enterprises to form a systematic thinking habit, which will drive the enterprise to consider the various issues and risks comprehensively to enhance the ability of resist risks. Secondly, learning organization can promote the enterprise organization to improve financial management level and salary management level. Learning based financial system and salary management system will determine the salary difference according to the behavior and ability of the job holder. Evaluation indicators will also focus on the learning behavior of the members, the improving of ability and skills, the changes of mental model, knowledge innovation and other aspects of the development.

\subsection{The Construction Mode of Knowledge Innovation of Learning Organization}

The mode of knowledge innovation of learning organization reveals the innovation mechanism of internal knowledge. In the learning organization, the main body of knowledge innovation is multiple team members and the organization. So, it is necessary to study the knowledge transfer process among members and teams to research knowledge innovation model.

The initial prototype of the SECI model is presented in a book by Ikujiro Nonaka and Hirotaka Takeuchi in 1995.The book is The Knowledge-Creating Company, which proposed a unique view towards the knowledge management framework of Japanese enterprises, presenting new understanding of the the knowledge creation and knowledge management. Ikujiro Nonaka divides the enterprise knowledge into tacit knowledge and explicit knowledge. The tacit knowledge includes belief, metaphor, intuition, thinking mode and so called "know-how", while explicit knowledge can be spread through normalized and systematized language, also known as the knowledge of the text. Ikujiro Nonaka also proposed that in the process of enterprise innovation activities tacit knowledge and explicit knowledge are mutually interacted and transformed. The process of knowledge transformation is actually the process of knowledge creation. There are four basic modes of knowledge transformation -- Socialization, Externalization, Combination and Internalization.

On the basis of drawing lessons from the traditional SECI innovation model, this paper will overcome the disadvantage of the SECI model which is only pay attention to the knowledge innovation of the members and ignore the external social knowledge also has great influence in the production of enterprise knowledge. Especially in today's highly developing information technology, any enterprise must be good at fast learning social knowledge, and make quick response. In addition, according to the SECI model, the knowledge of the enterprise organization must be refined into the tacit knowledge of all members, so it will becomes the "conscious behavior" of all members. In other words, the carrier of the core knowledge of the enterprise is all the members of organization. But in real life, we can find that many enterprises staff flow rate is extremely frequent and large. When the economy is in a severe recession, many large manufacturing enterprises will reduce the risk by large-scale layoffs, but it does not affect its dominant position in the core technology. It also shows that the storage and process of 
organizational knowledge is quite complex, and the SECI model can not explain many key problems in the process of

enterprise knowledge production.

Learning organization knowledge innovation model:

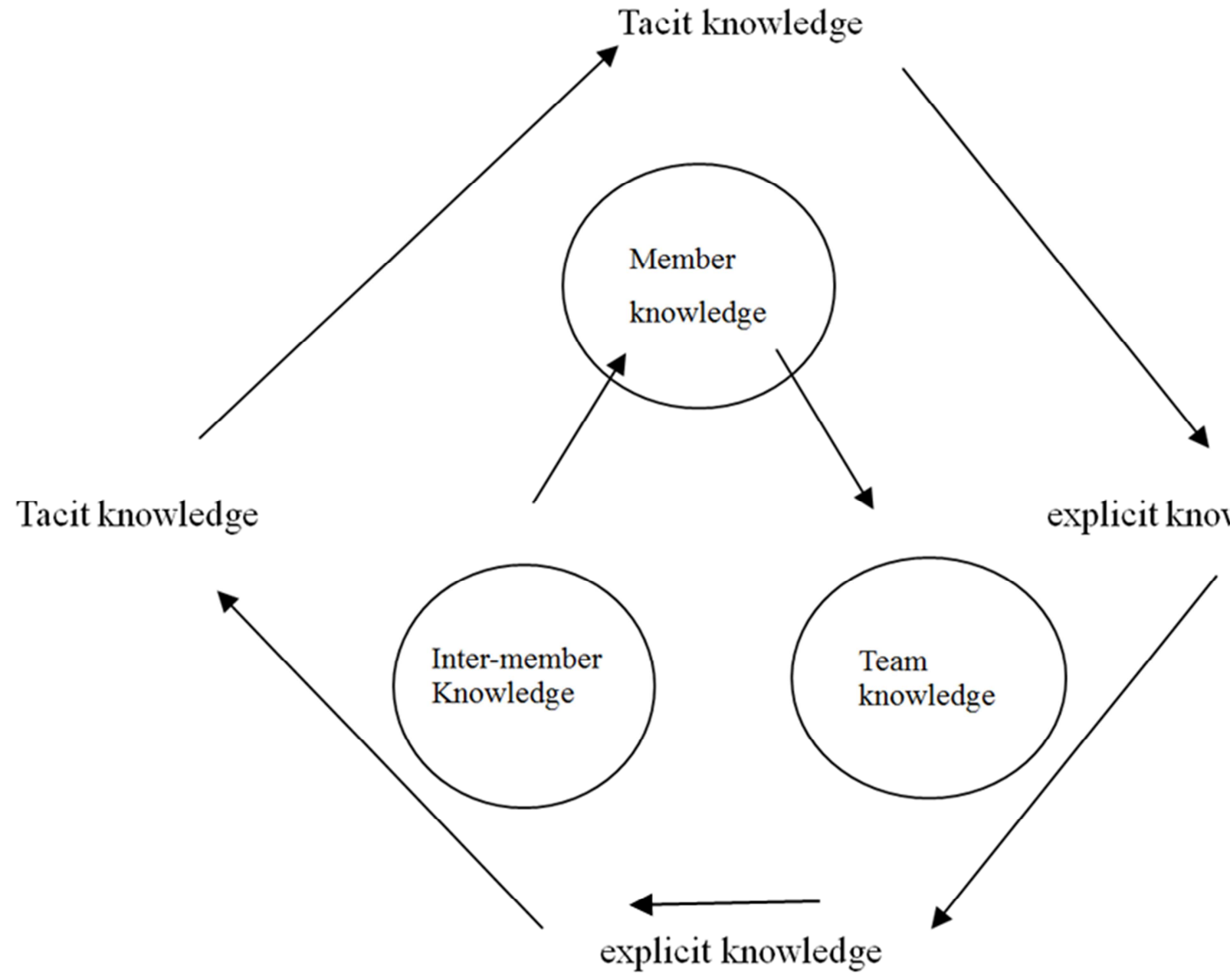

Figure 1. Learning organization knowledge innovation model.

This study shows the knowledge innovation process of learning organization is summarized as two modes: the member knowledge innovation and the team knowledge innovation.

(1) The member knowledge innovation. First of all, the team itself does not create knowledge, each member in the daily work of experiences different learning process. Members absorb their own past experience, insights, and form a certain view to the problems in their own mind. When the team members gather together to express their views, they make the tacit knowledge become the explicit knowledge, which is the process of knowledge innovation. Thus no matter the learning and growing or the knowledge innovation of members are achieved in the social community and the environment.

(2) The team knowledge innovation. Team knowledge innovation can be accomplished through the socialization, externalization, combination and the internalization process. Socialization is the transformation of tacit knowledge to tacit knowledge, such as the direct interaction between the company and the suppliers and customers. The transformation from tacit knowledge to explicit knowledge is an important link in the process of knowledge creation. Combination is a combination of explicit knowledge and explicit knowledge. It is a language or digital symbol produced by a variety of media, and a systematic process of a variety of explicit concepts. Internalization is the transformation of explicit knowledge to tacit knowledge, and it is a process of visualization and concretion. Team knowledge innovation can drive the pace of innovation in all aspects of the enterprise, so as to improve the core competitiveness of enterprises, enhance the vitality and vitality of enterprises.

\subsection{Construction of Learning Organization Incentive Mechanism}

The establishment of motivation mechanism in learning organization can give full play to the initiative and enthusiasm 
of the members. First of all, enterprises should fully affirm and appropriate incentives the member who makes contribution for the construction of learning oriented organizations. So that employees can enhance the internal power to participate in the construction activities.

\subsection{Information System Construction of Learning Organization}

At present, many well-known large companies in the world have their own knowledge management system. The establishment of knowledge management system of enterprise organization should be based on the enterprise network and the development of information technology, which can promote the enterprise's knowledge resources to be able to transfer and share between the Department and the staff. In addition, during the information construction of enterprise, the organization should pay attention to the human, financial, material resources and the integration of information technology investment. Because the integration of enterprise information technology can guarantee the enterprise's material flow and capital flow in good condition in the whole organization, which is conducive to the realization of the optimal allocation of resources within the organization.

\section{Conclusion}

The 21 st century is the era of knowledge economy, the production, dissemination, exchange and utilization of knowledge have become important driving forces for economic growth. In the final analysis, the competition of enterprises is not only the competition of learning ability, but also the competition of knowledge. To improve the organizational learning ability and innovation ability, is the key for the formation of the core competitiveness of enterprises. The learning organization theory provides a new perspective and method. Learning organization based on knowledge management, is to make the enterprise become a organization which is good at learning knowledge, creating knowledge, and continuously improving the competitiveness of the organization. In the process of building a learning organization, the enterprise should focus on the management of performance, ability and knowledge, so as to improve the ability of organization and management innovation. In order to construct a flexible and efficient flat organizational structure, the organizations need to reform. The organization should promote the learning of the organization through setting up the value of learning and the transformation of staffs' mental model. Constructing learning organization incentive mechanism is to stimulate the enterprise's core competitiveness, and through the construction of information system, to improve the efficiency of resource use and the level of knowledge sharing, and promote the healthy operation of knowledge capital finally.

\section{Acknowledgements}

This study was supported by Wuhan Donghu University
Institute of agricultural e-commerce in Hubei province Collaborative Innovation Center (cultivation) [2015] 11.

\section{References}

[1] Karl Wig. Knowledge Management, an Introduction, Proceedings of IAKE Second Annual International.

[2] Mike Pedler. A Guide to the Learning Organization [J]. Industrial and Commercial Training, 1995, 27 (4): 21-25.

[3] Rifkin W, Fulop 1. A Review and Case Study on Learning Organizations [J]. The Learning Organization, 1997, 4 (4): $135-148$.

[4] Zhang Qian. Division of knowledge management and learning organization integration stage. Scientific and technological progress and Countermeasures [J]. 2008, 25 (8): 175-176.

[5] Ding Wei. Knowledge management systems - tools for building learning organization. Library and information work. 2001 (6): 5-8.

[6] Qiu Junping. Knowledge management science [M]. Bei Jing: Science and Technology Literature Press. 2006: 178-180.

[7] Peter M. Senge. The fifth discipline: The art and practice of the learning organization [J]. New York: Doubleday Currency, 1990.

[8] Collis D. J. How valuable Are organizational Capabilities. Strategic Management Journal, 1994 (15).

[9] Argyris C. Action Science and organizational Learning [J]. Journal of Managerial Psychology, 1995 (10).

[10] Hedlund G, A model of knowledge management and the N-form corporation. Strategic Management Journal, 1994, 15 (1).

[11] Argyris C, Schon DA. Organizational Learning: A Theory of Action Perspective [M]. Reading, MA: Addision-Wesley, 1978.

[12] De Geus, A. The living company [M]. Boston, MA: Harvard Business School Press, 1997.

[13] Huber, G. P. Organizational learning: The contributing process and the literatures [J]. Organization science. 1991, 2: 88-115.

[14] Ji Hoon Song, Baek-Kyoo (Brian) Joo, and Thomas J. Chermack. The Dimensions of Learning Organization Questionnaire (DLOQ): A Validation Study in a Korean Context [J]. Human resource development quarterly, 2009, 21 (1).

[15] Mosammod Mahamuda Parvin, MM Nurul Kabir. Factors Affecting Employee Job Satisfaction of Pharmaceutical Sector [J]. 2011, 1 (9): 113-123.

[16] L. van Schalwyk \& S. Rothmann. Job satisfaction in a chemical factory [J]. Southern African Business Review, 2010, $14(3)$.

[17] Brikend Aziri. Job satisfaction: A Literature Review [J]. Management Research and Practice, 2011, 3: 77-86.

[18] Baek-Kyoo (Brain) Joo. Leader -Member Exchange Quality and In-Role Job Performance: The Moderating Role of Learning Organization Culture [J]. Journal of Leadership \& Organizational Studies, 2012. 02, 19 (1): 25-34. 
[19] Daniel Dauber, Gerhard Fink, Maurice Yolles. A Configuration Model of Organizational Culture [J]. Sage Open, 2012. 03, 2 (1).
[20] Chen, X: Empirical Study on the Relationship between Tacit Knowledge Creation and the Evolution of Core Competence [C]. In D. Zeng (ed), ICAIC (2), 2011: 523-530. 